\title{
Contribution of Vascular and Neural Segments to Baroreflex Sensitivity in Response to Postural Stress
}

\author{
Nazia P. Saeed Robert S. Reneman Arnold P.G. Hoeks \\ Departments of Biophysics and Physiology, Cardiovascular Research Institute Maastricht, Maastricht University, \\ Maastricht, The Netherlands
}

\section{Key Words}

Arterial blood pressure $\cdot$ Baroreceptor sensitivity $\cdot$ Carotid artery diameter $\cdot$ Distension $\cdot$ Neural segment $\cdot$ Postural changes $\cdot$ Vascular segment

\begin{abstract}
Background/Aims: The baroreflex pathway has a vascular and a neural segment, both being modulated by variations in peripheral blood pressure (BP). Besides overall baroreceptor sensitivity (BRS), defined as the spectral relationship between changes in peripheral BP and R-R interval within the frequency band of $0.05-0.15 \mathrm{~Hz}$, vascular and neural segment contributions to the overall BRS can be distinguished. We test the hypothesis that changes in overall BRS following a postural maneuver mainly originate from the vascular (peripheral pressure to carotid artery diameter) rather than the neural segment (carotid artery diameter to R-R interval). Methods: Peripheral pressure (Finapress), carotid artery diameter (ultrasound in B-/M-mode) and electrocardiogram values of 20 young subjects in supine and upright-seated postures were recorded simultaneously. Transfer gains were computed for the segmental and overall responses. Results: Postural change significantly increases peripheral BP and carotid artery diameter. The vascular segment has a uniform spectral distribution. Statistical analyses revealed that pos-
\end{abstract}

tural change decreased overall $(p<0.004)$ and vascular $(p<$ 0.0001 ) transfer gains, but did not modify neural gain. Conclusions: Unlike the neural segment, the vascular segment is frequency non-specific. The decrease in overall BRS due to a postural change is mainly explained by the reduced transfer gain of the vascular segment.

Copyright $\odot 2009$ S. Karger AG, Basel

\section{Introduction}

Baroreceptor sensitivity (BRS; $\mathrm{ms} / \mathrm{mm} \mathrm{Hg}$ ) quantifies the adaptation of the R-R interval to effectively counteract blood pressure (BP) changes by the baroreflex control mechanism. Clinically, BRS is, among others, associated with age $[1,2]$, orthostatic hypotension [3-5], risk of death after myocardial infarction [6], chronic renal failure, type II diabetes [7] and hypertension [8, 9]. The baroreflex is an important BP control mechanism [10, 11]; changes in $\mathrm{BP}$ are detected by baroreceptors, which are located in the aortic arch and in the sinuses of carotid arteries [12]. The baroreceptor signals affect heart rate and peripheral arterial resistance via a cerebral pathway [13].

This study was supported by a Marie Curie Excellence Grant (grant EU EST_514.421).

\section{KARGER}

Fax +41613061234 E-Mail karger@karger.ch www.karger.com
(C) 2009 S. Karger AG, Basel

$1018-1172 / 09 / 0465-0469 \$ 26.00 / 0$

Accessible online at:

www.karger.com/jvr
Prof. Arnold P.G. Hoeks

Department of Biophysics

Cardiovascular Research Institute Maastricht, Maastricht University

PO Box 616, NL-6200 MD Maastricht (The Netherlands)

Tel. +31 43388 1667, Fax +31 43388 4178, E-Mail a.hoeks@bf.unimaas.nl 


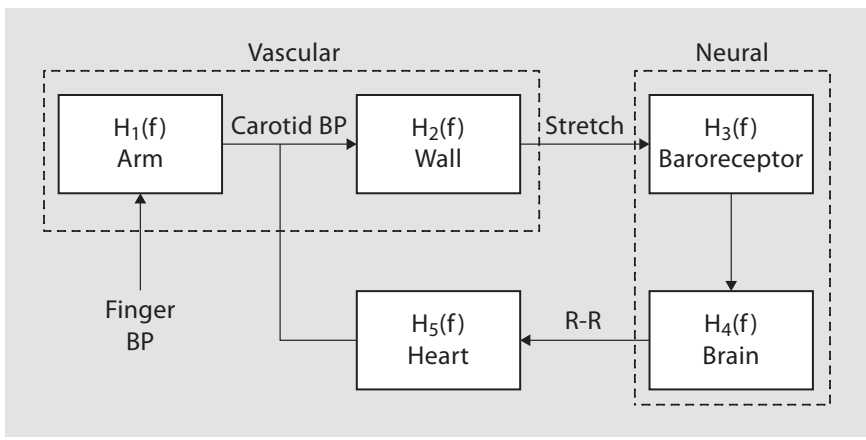

Fig. 1. Block diagram of segments (transfer functions) in the baroreflex loop and calculations of BRS. The transfer function $\mathrm{H}_{2}(\mathrm{f})$ represents the change in carotid $\mathrm{BP}$ estimated from the finger and the change in lumen diameter (circumferential wall strain) of the CCA. The functions $\mathrm{H}_{3}(\mathrm{f})$ and $\mathrm{H}_{4}(\mathrm{f})$ represent the stretch changes being translated by the baroreflex sensors and the brain into autonomic outflow to the heart, which in turn has an influence on the R-R interval length $\mathrm{H}_{5}(\mathrm{f})$. The calculated overall BRS is composed of the vascular segment (input BP; output stretch) and the neural segment (input stretch; output R-R interval).

Due to its commendable reproducibility [14], BRS is an attractive measure to quantify systemic responses to prevailing risk factors. As a result, techniques to quantify the BRS have been established in both time-domain and frequency-domain analysis of systolic peripheral BP and R$\mathrm{R}$ interval recordings [10]. Time-domain algorithms are based on the selection of simultaneously recorded segments of electrocardiogram (ECG) and peripheral BP. To calculate the BRS, a clear and consistent upward or downward trend in R-R interval and peripheral systolic BP (SBP) over 3 consecutive cardiac cycles is required [15, 16]. The BRS ( $\mathrm{ms} / \mathrm{mm} \mathrm{Hg}$ ) is then quantified by the ratio of the rate of change in R-R interval and in BP, averaged over as many as 10 segments. The contiguous series of $\mathrm{R}$ $\mathrm{R}$ intervals is also used to calculate statistical measures such as mean and standard deviation, the latter being a measure for heart rate variability [17]. Frequency-domain analysis or spectral analysis is applied to continuous BP and ECG signals, recorded under stationary conditions over several minutes $[10,18,19]$. The spectral relationship between the input signal (commonly SBP) and the output signal ( $\mathrm{R}-\mathrm{R}$ interval) is defined by the cross-correlation spectrum, which is the product of the Fourier transform of both signals $[17,20,21]$. Normalization of the absolute value of the cross-correlation spectrum $\left(\Phi_{\mathrm{pr}}\right)$ with respect to the spectral input power $\left(\Phi_{\mathrm{pp}}\right)$ provides the spectral gain $|\mathrm{H}(\mathrm{f})|$ (amplitude of the transfer function) of the control process.

$$
|\mathrm{H}(\mathrm{f})|=\frac{\left|\Phi_{\mathrm{pr}}\right|}{\Phi_{\mathrm{pp}}}
$$

The average or peak spectral gain within the frequency range from 0.05 to $0.15 \mathrm{~Hz}$ is generally considered as a suitable measure for BRS [20].

Because BP is a key input for the BRS estimate, its precision is highly significant. As BP measurements at the common carotid artery (CCA) level are impractical, the carotid artery BP measurement is substituted by a peripheral registration, i.e. pressure signals acquired from a radial or digital artery. The relationship between SBP levels at the peripheral and carotid locations is accounted for by Kornet et al. [2], by considering the transfer function $\mathrm{H}_{1}(\mathrm{f})$ between the peripheral registration site and the CCA in the detailed baroreceptor feedback loop as depicted in figure 1. With recently developed ultrasound techniques, it is possible to record the carotid wall deformation directly as a measure for wall strain, caused by local BP variation [22], which in figure 1 is represented by the node between $\mathrm{H}_{2}(\mathrm{f})$ and $\mathrm{H}_{3}(\mathrm{f})$.

Observed deviations in BRS $[5,23]$ can originate from different segments of the baroreflex loop $[24,25]$. Thus, by distinguishing the segments of the baroreflex loop, the element responsible for a disturbed feedback mechanism can be identified $[2,26,27]$. For the purpose of this study, the transfer gain from peripheral BP to wall deformation is referred to as the vascular segment (fig. 1). Similarly, the transfers from wall strain to baroreceptor activity $\left[\mathrm{H}_{3}(\mathrm{f})\right]$ to $\mathrm{R}-\mathrm{R}$ interval $\left[\mathrm{H}_{4}(\mathrm{f})\right]$, including responses of the nervous system to the heart, will be referred to as the neural pathway $[25,26]$. According to this concept, the overall transfer gain (BRS gain) should be the product of the vascular and neural gains. The concepts of vascular and neural segments should not be confused with the concepts of neural and peripheral arcs found in the literature $[26,27]$.

Previous studies have demonstrated that the overall BRS gain value reduces in response to evoked changes in peripheral BP, e.g. by exercise or postural maneuvers [11, 28]. In these studies, however, no distinction was made between contributions of vascular or neural segments. The postural maneuver is a reflection of normal physiological conditions; it is expected to induce a change in transmural carotid BP. Because arterial stiffness varies with average transmural BP, we hypothesize that the observed changes in overall BRS, when changing position, are mainly originating from the vascular rather than the neural segment of the control loop. This hypothesis will be tested in a group of young healthy subjects by simultaneous registration of signals at 3 nodes of the control loop (fig. 1). 


\section{Methods}

\section{Study Population}

Twenty young healthy volunteers (20-30 years, 10 males and 10 females) were recruited. All participants signed an informed consent before entering the study, which was approved by the joint medical ethical committee of the University Hospital Maastricht and the University of Maastricht.

\section{Anthropometric Measures and Questionnaires}

Height and weight were measured. Using a questionnaire, the participants were categorized into past, present or never smokers. All volunteers were normotensive (peripheral BP $\leq 140 / 90 \mathrm{~mm}$ $\mathrm{Hg}$ ), had no apparent cardiovascular disease and were free of medication.

\section{Signal Acquisition}

The ultrasound measurements were made using an adapted echo system (Scanner 350; Esaote Europe, Maastricht, The Netherlands) equipped with a $7.5-\mathrm{MHz}$ linear array transducer. The data acquisition system samples the radiofrequency signals received together with two reference and two trigger signals. It has a sample frequency (synchronous to the emission trigger of the attached echo system) with a maximum of $30 \mathrm{MHz}$ and a dynamic range of $72 \mathrm{~dB}$ (12 bit). The reference channels and trigger signals are sampled at the pulse repetition frequency, i.e. the rate at which a new radiofrequency line is received [29]. For this application, the pulse repetition frequency was $580 \mathrm{~Hz}$, while peripheral BP and ECG are used as reference signals. Using the R-top of the ECG as a synchronization point, dedicated signal processing [30] provides a continuous output of end-diastolic diameter and the variation in diameter over a cardiac cycle (distension waveform) based on the evaluation of half-overlapping signal segments with a duration of $21 \mathrm{~ms}$. Even though the ultrasound system interlaces $\mathrm{B}$ - and $\mathrm{M}$-mode, the configuration allows selective capturing of ultrasound signals generated in M-mode only. Unfortunately, this selective capture is only operational in pulsed Doppler $\mathrm{M}$-mode rather than in echo M-mode, resulting in a lower resolution along the line of observation. As the echo system provides visual feedback in B-mode concerning the position and orientation of the selected Doppler M-line, recordings over a long period of time (3 $\mathrm{min})$ become feasible.

\section{Protocol}

Subjects refrained from exercise, food and coffee consumption for a minimum of $2 \mathrm{~h}$ prior to the examination. The subject was asked to adopt a supine position (fig. 2). A Finapress system (Ohmeda, Engelwood, Colo., USA) cuff was placed on the middle phalanx of the third finger for peripheral arterial BP measurement with the hand positioned at heart level. A three-lead ECG was applied for registering heart rate as well as deriving a trigger for the ultrasound registration. To avoid the confounding effect of temperature on BP, the subject was covered with a blanket [31].

To enable regular resting breathing patterns and normalization of heart rate and $\mathrm{BP}$, we allowed for a period of rest $(5 \mathrm{~min})$ before commencing any measurements. Subjects were provided with light entertainment in the form of television to improve relaxation conditions.

After positioning the M-line $2 \mathrm{~cm}$ proximal to the bifurcation point, signal acquisition and processing were initiated. Each reg-

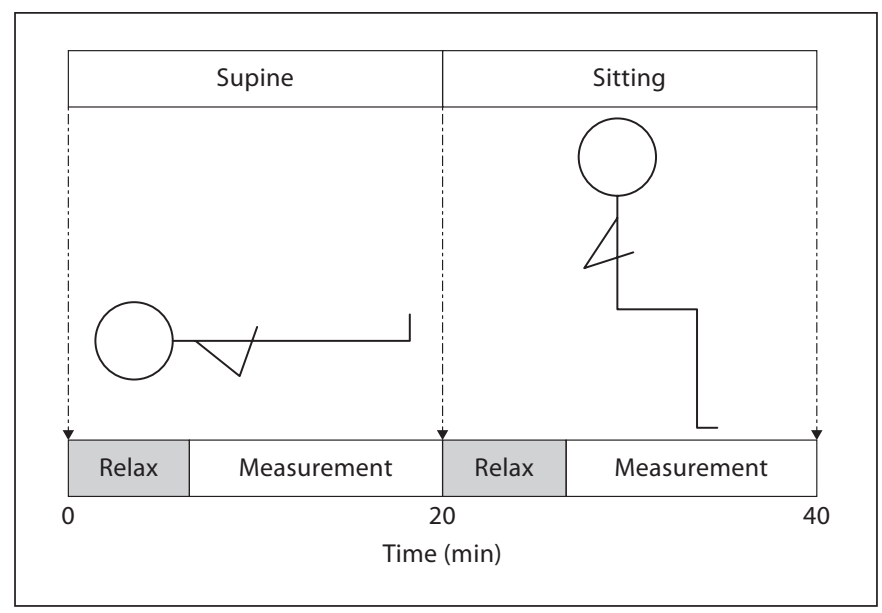

Fig. 2. Diagrammatic overview of the protocol timeline. Prior to measurements, subjects had 10-min relaxation periods, also used to calibrate the BP system.

istration lasted $3 \mathrm{~min}$ and was repeated thrice. The subject then moved to a sitting upright position with the finger BP cuff stabilized at heart level. After a 5-min normalization period, the measurement sequence was repeated (fig. 2). Calibration of the BP measurement system was only enabled during the relaxation periods.

\section{Calculation of Transfer Functions}

From the BP and diameter signals, relevant values (diastolic, systolic and pulse diameter; rate of change of diameter and pressure) are extracted on a beat-to-beat basis, constituting the signals for further processing. The rate of change in the pressure or the diameter waveform is defined as the difference between a 10 and $90 \%$ level of the systolic upstroke divided by the associated rise time.

BRS was calculated by applying the frequency method to corresponding segments of pressure, diameter and R-R interval signals $[2,32]$. Briefly, all signals were resampled at a fixed time base with a sample interval of $1 \mathrm{~s}(1 \mathrm{~Hz})$. The signals extracted from the repeated measurements were split up in half-overlapping segments, each with a length of 128 sample points (seconds). After removal of a first-order trend, the segments of the selected signal combination $x(t)$ and $y(t)$ were transformed to the frequency domain with a spectral resolution of $\sim 0.01 \mathrm{~Hz}$, providing $X_{s}(f)$ and $Y_{s}(f)$. Using ensemble averaging [33] over the $s$ available spectral segments and spectral averaging over 3 adjacent frequency bins, estimates of the power spectrum $\Phi_{x x}(f)$, coherence $\gamma^{2}(f)$, the cross-spectrum $\Phi_{x y}(f)$ and the transfer function $H(f)$ were calculated:

$$
\begin{aligned}
& \widehat{\Phi}_{x x}(f)=\frac{\sum_{s} X(f) X^{*}(f)}{s} \\
& \widehat{\Phi}_{x y}(f)=\frac{\sum_{s} X(f) Y^{*}(f)}{s}
\end{aligned}
$$




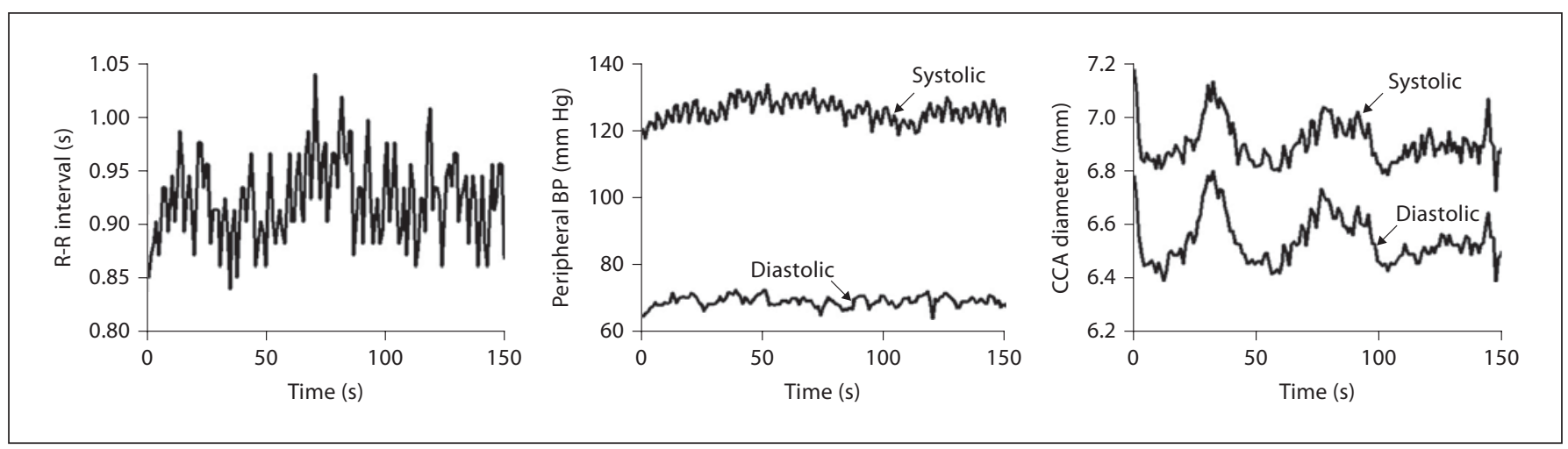

Fig. 3. Temporal behavior of the input signals R-R interval (left), SBP and DBP (middle), and systolic and diastolic diameter (right) from 1 subject in the supine position. Measurements of diameter were performed in the CCA. Arterial pressure was recorded in the finger.

$$
\begin{aligned}
\widehat{\gamma}_{x y}^{2}(f) & =\frac{\left|\Phi_{x y}(f)\right|^{2}}{\Phi_{x x}(f) \Phi_{y y}(f)} \\
|\hat{H}(f)| & =\frac{\left|\widehat{\Phi}_{x y}(f)\right|}{\widehat{\Phi}_{x x}(f)}
\end{aligned}
$$

The spectral values were averaged over the low-frequency range of $0.05-0.15 \mathrm{~Hz}$ to arrive at final estimates. Transfer function values were considered as significant when the coherence value indicated that the considered signals contained a common component rather than noise. Given the number of segments and the degree of overlap, the threshold value $(\mathrm{p}=0.05)$ is set at 0.14 $[22,34]$.

\section{Statistical Analysis}

Means \pm SD were calculated for temporal and spectral parameters. The intra- and inter-subject coefficients of variations (ratio of standard deviation and mean) are expressed as percentages.

To check whether parameters and the transfer function values had a normal distribution, a Kolmogorov test statistic was calculated (using Matlab functions). A Mann-Whitney U test (also known as 'rank' test, being a non-parametric function) was applied to all parameters and transfer functions to test the level of significance for differences induced by the postural maneuver.

The Mann-Whitney $U$ test was also applied to the estimated and calculated (product of neural and vascular) overall BRS values, to evaluate the consistency of this method.

\section{Results}

\section{Study Group Characteristics}

The average population height and weight was $1.78 \pm$ $0.08 \mathrm{~m}$ and $70 \pm 10 \mathrm{~kg}$, respectively. Figure 3 shows an example of the spontaneous temporal behavior of the input signals for 1 subject in supine position. Three subjects were excluded from further analyses, based on invalid recordings of peripheral $\mathrm{BP}$, resulting in a population of 17 subjects ( 9 males and 8 females). The cardiovascular characteristics in the supine and sitting positions are listed in table 1 . The average $\mathrm{BP}$, heart rate and arterial diameter values were determined over the total recording time $(10 \mathrm{~min})$ per position. The intra-subject coefficient of variation ranged from 3 to $9 \%$ for heart rate, end-diastolic carotid diameter and peripheral BP. Postural change from the supine to the sitting position resulted in a significant increase in peripheral (diastolic BP (DBP), mean BP and SBP) BP and a significant decrease in end-diastolic carotid diameter (table 1). The increases in heart rate and distension were not statistically significant.

For all subjects, in both positions and all signal combinations, the coherence value for the baroreceptor frequency range was higher than the significance level of 0.14 , confirming significant common signal components. The cross-power spectral density distributions and the transfer functions exhibited relatively high peaks for the baroreceptor frequency range. There was no statistically significant difference between the average values for parameters or transfer function values between genders.

\section{Overall BRS}

The transfer gain values for both postures are listed in table 2. For reasons of comparability with other authors, and as no trend differences could be identified between the diastolic and systolic transfer gains, the transfer gains 
Table 1. Characteristics of the study group

\begin{tabular}{|c|c|c|c|c|c|}
\hline \multirow[t]{2}{*}{ Characteristics } & \multicolumn{3}{|c|}{ Means $\pm \mathrm{CV}(\%)$} & \multicolumn{2}{|c|}{ Average PSD (range) } \\
\hline & supine & sitting & $\mathrm{p}$ value $^{\mathrm{a}}$ & supine & sitting \\
\hline $\mathrm{R}-\mathrm{R}$ interval, $\mathrm{ms}$ & $1,030 \pm 12$ & $983 \pm 11.9$ & 0.192 & $0.23(0.16-0.57)$ & $0.11(0.08-0.16)$ \\
\hline End-diastolic diameter, $\mu \mathrm{m}$ & $6,703 \pm 7.1$ & $6,473 \pm 7.3$ & 0.005 & $56(42-65)$ & $21(14-28)$ \\
\hline Distension, $\mu \mathrm{m}$ & $565 \pm 28$ & $660 \pm 20$ & 0.073 & $0.13(0.08-0.22)$ & $0.04(0.01-0.09)$ \\
\hline Pulse pressure, $\mathrm{mm} \mathrm{Hg}^{\mathrm{a}}$ & $52 \pm 31$ & $54 \pm 33$ & 0.049 & $2.3(1.2-4.0)$ & $1.3(0.5-1.7)$ \\
\hline $\mathrm{DBP}, \mathrm{mm} \mathrm{Hg}^{\mathrm{a}}$ & $71 \pm 16$ & $88 \pm 14$ & 0.000 & $2.1(1.6-3.2)$ & $1.3(0.5-1.9)$ \\
\hline $\mathrm{SBP}, \mathrm{mm} \mathrm{Hg}^{\mathrm{a}}$ & $123 \pm 16$ & $142 \pm 15$ & 0.000 & $5.3(3.1-7.6)$ & $2.0(1.3-3.2)$ \\
\hline Mean arterial pressure, $\mathrm{mm} \mathrm{Hg}^{\mathrm{a}}$ & $85 \pm 13$ & $102 \pm 13$ & 0.000 & $4.7(2.6-4.1)$ & $1.4(0.4-1.9)$ \\
\hline
\end{tabular}

Table 2. Means \pm CV (\%) of considered transfer gains (in the study population), averaged over the baroreceptor frequency range (indicated with an $\mathrm{x}$ )

\begin{tabular}{|c|c|c|c|c|c|c|c|c|c|c|c|}
\hline \multirow[t]{2}{*}{ Segment } & \multirow[t]{2}{*}{$\begin{array}{l}\text { ECG } \\
\text { RR }\end{array}$} & \multicolumn{3}{|c|}{$\begin{array}{l}\text { Arterial finger } \\
\text { pressure }\end{array}$} & \multicolumn{3}{|c|}{ CCA diameter } & \multicolumn{4}{|c|}{ Transfer gain } \\
\hline & & PS & PED & $\Delta \mathrm{p}$ & DS & DED & $\Delta \mathrm{d}$ & supine & sitting & $\mathrm{p}$ value & $\Delta \%$ \\
\hline $\mathrm{O}$ & $\mathrm{x}$ & $\mathrm{x}$ & & & & & & $17.1 \pm 25$ & $9.8 \pm 34$ & 0.004 & 49 \\
\hline $\mathrm{O}$ & $\mathrm{x}$ & & $\mathrm{x}$ & & & & & $26.4 \pm 65$ & $14.2 \pm 51$ & 0.062 & 46 \\
\hline $\mathrm{O}$ & $\mathrm{x}$ & & & $\mathrm{x}$ & & & & $27.7 \pm 63$ & $15.6 \pm 51$ & 0.031 & 43 \\
\hline $\mathrm{V}$ & & $\mathrm{x}$ & & & $\mathrm{x}$ & & & $27.6 \pm 30$ & $8.7 \pm 39$ & 0.000 & 68 \\
\hline $\mathrm{V}$ & & & $\mathrm{x}$ & & & $\mathrm{x}$ & & $39.0 \pm 43$ & $10.6 \pm 53$ & 0.000 & 73 \\
\hline $\mathrm{V}$ & & & & $\mathrm{x}$ & & & $\mathrm{x}$ & $21.7 \pm 58$ & $8.11 \pm 59$ & 0.000 & 63 \\
\hline $\mathrm{N}$ & $\mathrm{x}$ & & & & $\mathrm{x}$ & & & $0.42 \pm 69$ & $0.26 \pm 73$ & 0.538 & 38 \\
\hline $\mathrm{N}$ & $\mathrm{x}$ & & & & & $\mathrm{x}$ & & $0.43 \pm 58$ & $0.29 \pm 41$ & 0.135 & 37 \\
\hline $\mathrm{N}$ & $\mathrm{x}$ & & & & & & $\mathrm{x}$ & $0.96 \pm 48$ & $0.64 \pm 39$ & 0.097 & 66 \\
\hline
\end{tabular}

$\mathrm{O}=$ Overall ( $\mathrm{ms} / \mathrm{mm} \mathrm{Hg}) ; \mathrm{V}=$ vascular $(\mu \mathrm{m} / \mathrm{mm} \mathrm{Hg}) ; \mathrm{N}=$ neural $(\mathrm{ms} / \mu \mathrm{m}) ; \Delta \%=$ percent difference from supine (for each subject). Systolic (PS), end-diastolic (PED) and pulse ( $\Delta \mathrm{p}) \mathrm{BP}$, and systolic (DS), end-diastolic $(\mathrm{DED})$ and pulse $(\Delta \mathrm{d})$ carotid diameters are shown.

referred to further on in the study will be based on peripheral SBP, carotid systolic diameter and R-R interval, even though posture effects on DBP and pulse values are more pronounced (table 2). Figure 4 illustrates the transfer gain and coherence plots of the peripheral systolic pressure to the R-R interval for 1 subject in supine position. The statistical test showed a highly significant $(\mathrm{p}<0.004)$ decrease in the overall baroreceptor gain of $49 \%$ between the supine and sitting upright postures (table 2).

\section{Neural and Vascular Segments}

Figure 4 illustrates the spectral gain distribution for the neural and vascular segments. Unlike the neural and overall transfer gain plots, the vascular transfer gain plot had a uniform spectral distribution. The high coherence over the entire frequency range confirms that this uniform distribution is not artifactual. Statistical analysis of the segments demonstrated a significant decrease of $68 \%$ $(\mathrm{p}<0.0001)$ in the vascular gain value from supine to sitting (table 2), and a statistically insignificant decrease of $38 \%(\mathrm{p}=0.54)$ in the neural segment (table 2).

The transfer gains did not have a normal distribution, as shown by the Kolmogorov test. Therefore, the difference between the calculated and estimated overall BRS gain was also tested with a rank test. For each posture (supine and sitting), the products of the transfer function gains (12.5 \pm 4.1 and $4.3 \pm 2.4$, respectively) were consistent with the overall gain values $(17.1 \pm 4.3$ and $9.8 \pm$ 

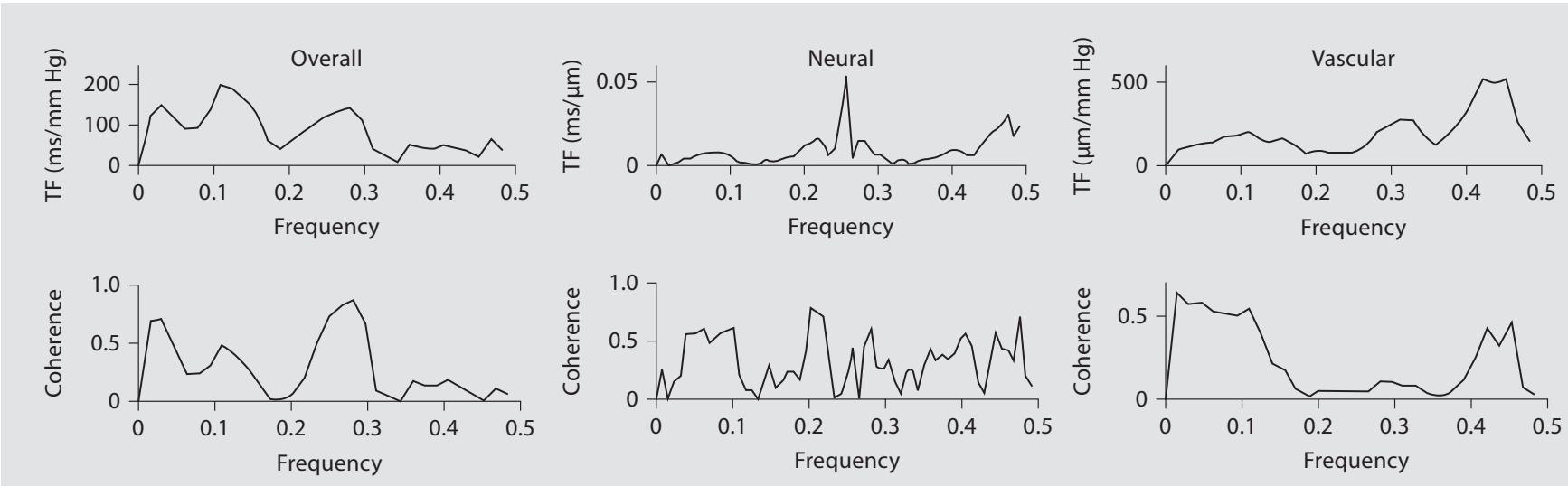

Fig. 4. The upper plot illustrates the transfer gain (TF) of an input to an output variable; the lower plot depicts the coherence spectrum of the same variables for 1 subject in the supine position. Left: SBP to R-R interval (overall transfer); middle: carotid systolic diameter to R-R interval (neural transfer); right: peripheral SBP to carotid systolic diameter (vascular transfer).

3.3, respectively). For both postures, the difference between the overall BRS and the product of the vascular and neural component, an estimate of overall BRS, was not statistically significant (supine: $\mathrm{p}=0.28$, and sitting: $\mathrm{p}=$ $0.49)$.

\section{Discussion}

This study demonstrates that a change in posture from supine to seated attenuates the overall BRS, corroborating the results of other studies [15, 35-37]. In addition, the separate identification and quantification of the response of the vascular and neural segments to a postural maneuver show for the first time that the vascular segment has a distinctive response (illustrated by a uniformly distributed transfer gain) and contributes dominantly to the depreciated overall BRS gain. The transfer gain of the neural pathway does not change significantly with posture.

\section{Effect of Postural Stress on BP, R-R Interval and Strain}

The baroreflex and vascular resistance control shortterm BP buffering; the exact mechanisms and their relationships have not been clearly identified. Even so, it is unknown whether the system is linear. The changes we observed as a result of shifting from supine to sitting upright are elevation of peripheral BP and reduced end-diastolic carotid artery diameter. These observations suggest that changes in pressure are counteracted by the barore- flex modulated through adaptation of the carotid artery diameter. However, the 3-9\% variation seen in artery diameter and distension as a result of a posture change are within the normal variation range, being opposed to larger induced changes, e.g. in studies using techniques such as neck suction [38], which may also provoke responses of other systems than the baroreflex.

The end-diastolic diameter of the carotid artery was found to be significantly smaller in the sitting than in the supine position (table 1). Assuming that the end-diastolic diameter changes linearly with end-diastolic pressure [39], then a decrease in the end-diastolic diameter by $3.5 \%$ in the sitting position $(6,703-6,473 \mu \mathrm{m}$; table 1$) \mathrm{im}$ plies a DBP drop of $3.5 \%$ at the carotid level. The BRS changes in response to absolute pressure and rate of pressure changes (change in pulse pressure) are well known [39]. Our subjects showed only a marginal increase in peripheral pulse pressure (table 1) as a result of postural change. If indeed changes in pulse pressure do stimulate the baroreceptor loop, then pulse pressure changes are inherently attenuated. According to the concept of the baroreflex control mechanism, heart rate should increase (reduced R-R interval) after the postural intervention [15, 31], which was observed, even though the level of statistical significance was not reached.

In our study on healthy young subjects, the posture change induced a larger distension of the carotid artery $(+16 \%)$ at a smaller diameter $(-4 \%)$, resulting in an increased pulsatile wall strain. The smaller end-diastolic diameter in the upright position requires an increased 
distension to accommodate the same amount of blood volume flow as in the supine position. This hypothesis is supported by observations that flow-mediated dilatation is more pronounced when the initial arterial diameter is smaller [40].

\section{Transfer Functions Estimating BRS}

In the present study, we observed a reduction in BRS of approximately $40 \%$ for the overall and of $70 \%$ for the vascular gain values. The former observation is in agreement with the findings of other studies in response to postural maneuvers such as moving from supine to headup tilt, sitting upright or standing $[15,16]$. Irrespective of subject age, both a head-up tilt and a change in posture induced a 50\% reduction in overall BRS gain $[41,42]$.

In contrast to previous approaches, in the present approach the carotid artery diameter node was included into the calculation of the baroreflex loop segments under steady-state conditions. A similar study previously segmented and identified components of the loop after pharmacological intervention [2,26,27], but the investigators did not draw any conclusions regarding the contribution of individual segments to the change in BRS. The observation that the calculated overall BRS, based on the product of the neural and vascular components, is not significantly different from the measured overall BRS indicates that the separate segments of the baroreceptor reflex are determined reliably. However, segmentation involves registration of additional parameters that introduce noise. Moreover, the transfer functions are based on small spontaneous fluctuations in the signals considered. Regarding the consistency and validity of the BRS values acquired by the spontaneous method [43], a panel of experts found that estimation of baroreflex function differed under physiological conditions [44]. The additional noise because of the extra node, in combination with the lower signal amplitude, explains the higher variability in the calculated overall gain compared to the overall gain estimated from peripheral BP and R-R interval recordings. On the other hand, our technique allows simultaneous registration of all involved parameters (peripheral pressure, carotid diameter and RR-interval).

We have shown that each segment has a unique transfer gain distribution and responds differently to a postural challenge. The spectral (gain) distribution of the neural segment exhibits specific peaks, which can be directly related to physiological processes (respiration and $\mathrm{BP}$ regulation). The transfer function of the vascular segment, on the other hand, has a uniform spectral distribution (fig. 4), implying that the vascular segment reacts immediately and adapts perpetually [13]. The uniform response is not surprising because under steady-state conditions the transfer gains from peripheral to carotid artery BP $\left(\left|\mathrm{H}_{1}(\mathrm{f})\right|\right)$ and from there to wall strain $\left(\left|\mathrm{H}_{2}(\mathrm{f})\right|\right)$ mostly involve mechanical transitions without a memory function.

We anticipated an increase in gain from pulse BP to strain $\left(\left|\mathrm{H}_{2}(\mathrm{f})\right|\right)$, based on the positive correlation between increased distension of the CCA (reduced stiffness) and $B R S$ gain values [45-47]. However, our results show a decrease in vascular and overall BRS gain, simultaneously with an increase in distension, which is contrary to other findings. Although this increase in distension with postural change can be justified, its associated drop in the vascular BRS gain value cannot, unless the transfer gain $\left|\mathrm{H}_{1}(\mathrm{f})\right|$ for peripheral to carotid BP is considerably reduced. A possible explanation is that in the sitting position peripheral vasoconstriction enhances peripheral pulse reflections; consequently, small BP perturbations at heart level are magnified at the peripheral recording site.

\section{Technical Criticism}

The aim of our study was to stimulate the baroreflex via a postural maneuver and monitor the response of this activity under steady-state conditions. Although a postural maneuver reflects physiological conditions, its small variations are prone to large errors. However, this is accounted for by extending the acceptance of the values through specific coherence evaluations (see Methods).

Earlier studies show the influence of respiration on the cross spectrum of BP and heart rate and hence BRS value $[48,49]$. In our implementation we considered only steady-state conditions with steady breathing, reducing possible modulations of the respiratory sinus arrhythmias and its effect on BRS gain value. We incorporated long-term (10-min) recordings of carotid artery characteristics to collect information about vascular responses. Particularly, recordings of the carotid artery in the supine position may be susceptible to motion artifacts (subject/ sonographer). However, the mean coherence within the baroreceptor frequency range did not change with position, indicating that possible errors were not related to the posture of the subject. The motion-incurred error is independent of the baroreceptor control mechanism and will have a uniform spectral distribution (noise). Aside of the interlaced B- and M-mode configuration, a cross-sectional view might improve the steadiness of the registration and thus noise. 


\section{Perspectives}

In conclusion, the results of our study show that the observed change in overall BRS due to a postural change is mainly explained by a downward shift in the transfer gain of the dominating vascular segment, which is frequency non-specific. The modulation of the neural segment response in this population appears to be negligible in comparison to that of the vascular segment. These intermediaries of the baroreflex analysis loop are relevant when questioning the cause of an observed dysfunctional baroreflex in clinical situations. Extending the interpretation of this study, one can articulate that BRS estimates measured as overall transfer gain values (peripheral SBP to RR interval) in healthy subjects (as is done in most studies) reflect to a high degree only the state of the vascular segment.
The results of this study demonstrate that a postural change stimulates the baroreflex pathway, resulting in an attenuated overall BRS transfer gain value, but only accompanied by a change in the vascular component, not in the neural segment. Therefore, for proper evaluation of the baroreceptor response under physiological and pathological circumstances, the neural and vascular segments have to be determined separately. This will also exclude the influence of changes in artery wall properties on overall BRS.

The distributed approach pursued in the current study provides a platform for selective differentiation of baroreflex control in populations with varying degrees of observed baroreflex activity, e.g. in aged subjects, to establish the contribution of the structure of the arterial wall in the ability of the baroreceptors to react to an arterial pressure change.

\section{References}

1 Honzikova N, Novakova Z, Zavodna E, Paderova J, Lokaj P, Fiser B, Balcarkova P, Hrstkova $\mathrm{H}$ : Baroreflex sensitivity in children, adolescents, and young adults with essential and white-coat hypertension. Klin Padiatr 2006;218:237-242.

-2 Kornet L, Hoeks AP, Janssen BJ, Houben AJ, De Leeuw PW, Reneman RS: Neural activity of the cardiac baroreflex decreases with age in normotensive and hypertensive subjects. J Hypertens 2005;23:815-823.

-3 Mansoor GA: Orthostatic hypotension due to autonomic disorders in the hypertension clinic. Am J Hypertens 2006;19:319-326.

-4 Mattace-Raso FU, van der Cammen TJ, Knetsch AM, van den Meiracker AH, Schalekamp MA, Hofman A, Witteman JC: Arterial stiffness as the candidate underlying mechanism for postural blood pressure changes and orthostatic hypotension in older adults: the Rotterdam Study. J Hypertens 2006;24:339-344.

5 Naschitz JE, Slobodin G, Elias N, Rosner I: The patient with supine hypertension and orthostatic hypotension: a clinical dilemma. Postgrad Med J 2006;82:246-253.

-6 La Rovere MT, Bigger JT Jr, Marcus FI, Mortara A, Schwartz PJ: Baroreflex sensitivity and heart-rate variability in prediction of total cardiac mortality after myocardial infarction. ATRAMI (Autonomic Tone and Reflexes After Myocardial Infarction) Investigators. Lancet 1998;351:478-484.
7 Johansson M, Gao SA, Friberg P, Annerstedt M, Bergstrom G, Carlstrom J, Ivarsson T, Jensen G, Ljungman S, Mathillas O, Nielsen FD, Strombom U: Reduced baroreflex effectiveness index in hypertensive patients with chronic renal failure. Am J Hypertens 2005; 18:995-1000; discussion 1016.

8 Grassi G, Trevano FQ, Seravalle G, Scopelliti F, Mancia G: Baroreflex function in hypertension: consequences for antihypertensive therapy. Prog Cardiovasc Dis 2006;48: 407-415.

9 Persson PB: Baroreflexes in hypertension: a mystery revisited. Hypertension 2005;46: 1095-1096.

10 Laude D, Elghozi JL, Girard A, Bellard E, Bouhaddi M, Castiglioni P, Cerutti C, Cividjian A, Di Rienzo M, Fortrat JO, Janssen B, Karemaker JM, Leftheriotis G, Parati G, Persson PB, Porta A, Quintin L, Regnard J, Rudiger H, Stauss HM: Comparison of various techniques used to estimate spontaneous baroreflex sensitivity (the EuroBaVar study). Am J Physiol Regul Integr Comp Physiol 2004;286:R226-R231.

11 Dietrich A, Riese H, van Roon AM, van Engelen K, Ormel J, Neeleman J, Rosmalen JG: Spontaneous baroreflex sensitivity in (pre)adolescents. J Hypertens 2006;24:345352.

12 Purves D, Augustine GJ, Fitzpatrick D, Hall WC, Lamantia AS, McNamara JO, Williams SM: Neuroscience, ed 2. Sunderland, Sinauer, 2001.

13 Chapleau MW, Hajduczok G, Sharma RV, Wachtel RE, Cunningham JT, Sullivan MJ, Abboud FM: Mechanisms of baroreceptor activation. Clin Exp Hypertens 1995;17:113.
14 Jira M, Zavodna E, Honzikova N, Novakova Z, Fiser B: Baroreflex sensitivity as an individual characteristic feature. Physiol Res 2006;55:349-351.

$\checkmark 15$ Bahjaoui-Bouhaddi M, Henriet MT, Cappelle $S$, Dumoulin G, Regnard J: Active standing and passive tilting similarly reduce the slope of spontaneous baroreflex in healthy subjects. Physiol Res 1998;47:227235.

16 Westerhof BE, Gisolf J, Stok WJ, Wesseling $\mathrm{KH}$, Karemaker JM: Time-domain crosscorrelation baroreflex sensitivity: performance on the EUROBAVAR data set. J Hypertens 2004;22:1371-1380.

17 Frenneaux MP: Autonomic changes in patients with heart failure and in post-myocardial infarction patients. Heart 2004;90: 1248-1255.

18 de Boer RW, Karemaker JM, Strackee J: On the spectral analysis of blood pressure variability. Am J Physiol 1986;251:H685-H687.

19 Eckberg DL, Kuusela TA: Human vagal baroreflex sensitivity fluctuates widely and rhythmically at very low frequencies. J Physiol 2005;567:1011-1019.

20 Kamath MV, Fallen EL: Power spectral analysis of heart rate variability: a noninvasive signature of cardiac autonomic function. Crit Rev Biomed Eng 1993;21:245-311.

21 Fazan R Jr, de Oliveira M, da Silva VJ, Joaquim LF, Montano N, Porta A, Chapleau MW, Salgado HC: Frequency-dependent baroreflex modulation of blood pressure and heart rate variability in conscious mice. Am J Physiol Heart Circ Physiol 2005;289: H1968-H1975. 
-22 Kornet L, Hoeks AP, Janssen BJ, Willigers JM, Reneman RS: Carotid diameter variations as a non-invasive tool to examine cardiac baroreceptor sensitivity. J Hypertens 2002;20:1165-1173.

-23 Pinna GD, Maestri R, Capomolla S, Febo O, Robbi E, Cobelli F, La Rovere MT: Applicability and clinical relevance of the transfer function method in the assessment of baroreflex sensitivity in heart failure patients. J Am Coll Cardiol 2005;46:1314-1321.

-24 Chapleau MW, Cunningham JT, Sullivan MJ, Wachtel RE, Abboud FM: Structural versus functional modulation of the arterial baroreflex. Hypertension 1995;26:341-347.

-25 Parati G, Lantelme P: Mechanical and neural components of the cardiac baroreflex: new insights into complex physiology. J Hypertens 2005;23:717-720.

-26 Ikeda Y, Kawada T, Sugimachi M, Kawaguchi O, Shishido T, Sato T, Miyano H, Matsuura W, Alexander J Jr, Sunagawa K: Neural arc of baroreflex optimizes dynamic pressure regulation in achieving both stability and quickness. Am J Physiol 1996;271:H882H890.

-27 Hunt BE, Fahy L, Farquhar WB, Taylor JA: Quantification of mechanical and neural components of vagal baroreflex in humans. Hypertension 2001;37:1362-1368.

-28 Linnarsson D, Spaak J, Sundblad P: Baroreflex impairment during rapid posture changes at rest and exercise after 120 days of bed rest. Eur J Appl Physiol 2006;96:37-45.

-29 Brands PJ, Hoeks APG, Willigers J, Willekes $\mathrm{C}$, Reneman RS: An integrated system for the non-invasive assessment of vessel wall and hemodynamic properties of large arteries by means of ultrasound. Eur J Ultrasound 1999; 9:257-266.

-30 Reneman RS, Meinders JM, Hoeks AP: Noninvasive ultrasound in arterial wall dynamics in humans: what have we learned and what remains to be solved. Eur Heart J 2005; 26:960-966.

-31 Tanaka H, Thulesius O, Borres M, Yamaguchi H, Mino M: Blood pressure responses in Japanese and Swedish children in the supine and standing position. Eur Heart J 1994;15: 1011-1019.
32 Persson PB, DiRienzo M, Castiglioni P, Cerutti C, Pagani M, Honzikova N, Akselrod S, Parati G: Time versus frequency domain techniques for assessing baroreflex sensitivity. J Hypertens 2001;19:1699-1705.

33 Welch PD: The use of the fast Fourier transform for the estimation of power spectra: a method based on time averaging over short, modified periodograms. IEEE Trans Audio Electroacoust 1967;AU-15:70-73.

34 Wang SY, Liu X, Yianni J, Christopher Miall R, Aziz TZ, Stein JF: Optimising coherence estimation to assess the functional correlation of tremor-related activity between the subthalamic nucleus and the forearm muscles. J Neurosci Methods 2004;136:197-205.

35 Green AL, Wang S, Owen SL, Paterson DJ, Stein JF, Aziz TZ: Controlling the heart via the brain: a potential new therapy for orthostatic hypotension. Neurosurgery 2006;58: 1176-1183; discussion 1176-1183

36 Carrasco-Sosa S, Gaitan-Gonzalez MJ, Gonzalez-Camarena R, Yanez-Suarez O: Baroreflex sensitivity assessment and heart rate variability: relation to maneuver and technique. Eur J Appl Physiol 2005:95:265-275.

37 Hunt BE, Farquhar WB, Taylor JA: Does reduced vascular stiffening fully explain preserved cardiovagal baroreflex function in older, physically active men? Circulation 2001;103:2424-2427.

38 Ogoh S, Volianitis S, Raven PB, Secher NH: Carotid baroreflex function ceases during vasovagal syncope. Clin Auton Res 2004;14: 30-33.

39 Klabunde RE: Cardiovascular Physiology Concepts. Philadelphia, Lippincott Williams, 2005.

40 Silber HA, Ouyang P, Bluemke DA, Gupta SN, Foo TK, Lima JA: Why is flow-mediated dilation dependent on arterial size? Assessment of the shear stimulus using phase-contrast magnetic resonance imaging. Am J Physiol Heart Circ Physiol 2005;288:H822H828.

41 Dawson SL, Robinson TG, Youde JH, Martin A, James MA, Weston PJ, Panerai RB, Potter JF: Older subjects show no age-related decrease in cardiac baroreceptor sensitivity. Age Ageing 1999;28:347-353; comment 337338.
42 Laitinen T, Niskanen L, Geelen G, Lansimies E, Hartikainen J: Age dependency of cardiovascular autonomic responses to head-up tilt in healthy subjects. J Appl Physiol 2004;96: 2333-2340.

43 Lipman RD, Salisbury JK, Taylor JA: Spontaneous indices are inconsistent with arterial baroreflex gain. Hypertension 2003;42:481487.

44 Parati G, Di Rienzo M, Castiglioni P, Bouhaddi M, Cerutti C, Cividjian A, Elghozi JL, Fortrat JO, Girard A, Janssen BJ, Julien C, Karemaker JM, Iellamo F, Laude D, Lukoshkova E, Pagani M, Persson PB, Quintin L, Regnard J, Ruediger JH, Saul PJ, Vettorello M, Wesseling $\mathrm{KH}$, Mancia G: Assessing the sensitivity of spontaneous baroreflex control of the heart: deeper insight into complex physiology. Hypertension 2004;43:e32e34; author reply e32-e34.

${ }_{45}$ Visontai Z, Lenard Z, Studinger P, Rigo J Jr, Kollai M: Impaired baroreflex function during pregnancy is associated with stiffening of the carotid artery. Ultrasound Obstet Gynecol 2002;20:364-369.

46 Steinback CD, O'Leary DD, Bakker J, Cechetto AD, Ladak HM, Shoemaker JK: Carotid distensibility, baroreflex sensitivity, and orthostatic stress. J Appl Physiol 2005; 99:64-70.

$\checkmark 47$ Mattace-Raso FU, van den Meiracker AH, Bos WJ, van der Cammen TJ, Westerhof BE, Elias-Smale S, Reneman RS, Hoeks AP, Hofman A, Witteman JC: Arterial stiffness, cardiovagal baroreflex sensitivity and postural blood pressure changes in older adults: the Rotterdam Study. J Hypertens 2007;25:14211426

48 Gerritsen J, TenVoorde BJ, Dekker JM, Kostense PJ, Bouter LM, Heethaar RM: Baroreflex sensitivity in the elderly: influence of age, breathing and spectral methods. Clin Sci (Lond) 2000;99:371-381.

49 Jovanov E: On spectral analysis of heart rate variability during very slow yogic breathing. Conf Proc IEEE Eng Med Biol Soc 2005;3: 2467-2470. 